\title{
Lenguaje y educación*
}

\section{Jorge Larrosa}

Universidad de Barcelona - Espanha
[...] sería provechoso si desistiésemos de la costumbre de oír siempre tan sólo lo que ya entendemos. Esta proposición no va dirigida sólo a cada oyente; va dirigida más aún a aquél que intenta hablar del habla -sobre todo cuando ello tiene lugar con la sola intención de mostrar posibilidades que nos permitan estar atentos al habla y a nuestra relación con ella.

\section{Martin Heidegger}

Durante su participación en las Conferencias Aranguren de Filosofía en su edición de 1994, José María Valverde ironizaba en la Residencia de Estudiantes de Madrid diciendo lo siguiente: "cierto ilustre filósofo actual empezaba un ensayo diciendo, más o menos - cito de memoria: 'En el horizonte de la filosofía, el lenguaje es uno de los temas más interesantes'. En realidad, debería ser al revés: 'En el horizonte del lenguaje, la filosofía es uno de los temas más interesantes'. Pues re-

* Este texto ha sido publicado en la obra coletiva Filosofia de la educación hoy; temas. (Madrid: Dykinson, 1998) sulta evidente, en efecto, que el lenguaje es el horizonte general de todo" (Valverde, 1995, p. 18-19). Sería entonces un error de perspectiva hablar aquí del lenguaje en el horizonte de la filosofía, en el horizonte de la pedagogía o incluso en el horizonte de la filosofía de la educación. Por eso, lo que voy a hacer a continuación es plantear algunas cuestiones filosófico-educativas en el horizonte del lenguaje. Y como el horizonte del lenguaje no es en absoluto el horizonte de la filosofía del lenguaje, mi trabajo no consistirá tampoco en destacar aquellos temas de la filosofía contemporanea del lenguaje que más puedan interesar a la educación.

Me gustaría partir, no de una disciplina o de un conjunto de disciplinas, sino de una inquietud, de la inquietud que la experiencia del lenguaje ha provocado en nuestro tiempo y principalmente, aunque no exclusivamente, en esa práctica lingüística cada vez menos especial y menos especializada que llamamos filosofía. Partir de la experiencia del lenguaje, tomar como punto de partida la inquietud sobre el lenguaje y en el lenguaje provocada en la experiencia misma del lenguaje, no es lo mismo que partir de nuestros conocimientos sobre el lenguaje. Cuando partimos de lo que sabemos sobre el lenguaje 
sólo oímos lo que ya entendemos. Pero en la experiencia del lenguaje, y quizá por eso es inquietante, lo que queda comprometido y suspendido es precisamente lo que ya sabemos, lo que ya entendemos, lo que ya oímos, lo que se deja capturar sin dificultad por el lenguaje cuando hablamos de ello (de los hechos, de los sucesos, de las cosas, de los problemas, de nosotros mismos, de nuestro lenguaje) precisamente porque no atendemos al ser del lenguaje mismo que habla.

He dividido lo que sigue en dos partes. En la primera de ellas se hace una apretadísima revisión de lo que la experiencia inquietante del lenguaje ha producido en los ámbitos de la escritura filosófica y de la escritura literaria. En dicha revisión se atiende sobre todo, aunque de una manera superficial y solamente indicativa, a aquellos aspectos de la ontología hermenéutica que están explícitamente implicados en cuestiones antropológicoeducativas. Puesto que la primera parte trata de preparar una atención al lenguaje que no pase necesariamente por su tematización objetivante, y puesto que esa preparación subvierte frontalmente la concepción representativa, expresiva y comunicativa del lenguaje que nos dan las ciencias y el sentido común, ha requerido un desarrollo relativamente extenso aunque yo creo que dotado de una cierta coherencia en la selección de autores, textos y problemas. Pero la extensión de esa fase preparatoria (con cuestiones educativas implícitas y susceptibles de un tratamiento especial que no se ha realizado) ha obligado que la segunda parte consista solamente en una breve serie de sugerencias para la reflexión que no pretende desde luego ser exhaustiva. La segunda parte del texto no es, entonces, otra cosa, que un conjunto de provocaciones para la reflexión y una muestra de lo que la ontología hermenéutica puede dar que pensar en el terreno educativo. Mi intención no es otra que mostrar posibilidades que nos permitan estar atentos al habla y a nuestra relación con ella (Heidegger, 1987, p. 144) o, dicho de otro modo, suscitar en el dominio educativo una atención y una sensibilidad al lenguaje y a nuestra relación con el lenguaje, inquietar esa relación, hacerla insegura y problemática y, si es posible, llevarla al pensamiento (y al lenguaje).

\section{La inquietud del lenguaje}

\begin{abstract}
[...] en todos sus dominios, por todos sus caminos y a pesar de todas las diferencias, la reflexión universal recibe hoy un movimiento formidable de una inquietud sobre el lenguaje - que no puede ser más que una inquietud del lenguaje y en el lenguaje mismo.
\end{abstract}

Jacques Derrida

Lo normal sería comenzar con la importancia de los hechos. Y decir, por ejemplo, como un hecho importante de la Filosofía, que el lenguaje se ha convertido en nuestro siglo en el objeto propio de una disciplina autónoma llamada Filosofía del Lenguaje. El hecho de nuestro tiempo sería entonces que la filosofía contemporánea ha seleccionado al lenguaje como un tema importante de reflexión, tan importante al menos como los otros temas que aborda en sus diversas subdisciplinas temáticas (la obra de arte en la estética, el valor en la filosofía de los valores, el hombre en la antropología filosófica, el conocer humano en la filosofía del conocimiento etc.).

O decir que la tematización filosófica del lenguaje ha supuesto en nuestro siglo un "giro" o un "viraje" de la filosofía misma en el sentido de que gran parte de los problemas filosóficos tradicionales tienden actualmente a tratarse a partir de la forma que adquieren en el lenguaje. El hecho de nuestro tiempo sería que la problematización filosófica del lenguaje ha atravesado todas las disciplinas filosóficas: a partir de la tematización del lenguaje, la teoría del conocimiento ha pasado de ser crítica de la razón a ser crítica del lenguaje, la antropología filosófica ha pasado a considerar al hombre como una entidad lingüística y a estudiar las correlaciones entre lenguaje y cultura, la ética se ocupa ahora de la justificación de las formas de lenguaje propias de los enunciados morales, y la estética habría pasado a considerar la obra de arte desde el punto de vista de su significado.

O decir que el lenguaje se ha convertido en el gran tema de las filosofías contemporáneas desde el 
estructuralismo a la filosofía analítica, pasando por la hermenéutica, la fenomenología o las distintas filosofías críticas o trascendentales y se ha convertido en una especie de punto de encuentro y de debate de gran parte de las corrientes filosóficas más importantes.

Siguiendo con la importancia de los hechos, también se podría decir, por ejemplo, como un hecho de la ciencia que interesa a la filosofía (a la filosofía del lenguaje y a la filosofía de la educación), que en nuestro siglo se han constituido por fin las ciencias positivas del lenguaje que van desde las distintas lingüísticas hasta la semiótica o la gramática comparada, pasando por la biología del lenguaje, la psicolingüística, la etnolingüística o la sociolinguiística. El hecho de nuestro tiempo sería que el lenguaje se ha convertido en el objeto de una serie amplísima de disciplinas y en un importantísimo dominio interdisciplinario.

Y también se podría decir, por ejemplo, como un hecho social o cultural en este caso, que nuestro tiempo es el tiempo de los lenguajes, el tiempo de la información y de la comunicación, el tiempo de la explosión de los sistemas de signos y de la proliferación de los medios de su circulación. Además, nuestro tiempo sería también el tiempo de la conciencia de la ubicuidad del lenguaje. La lingüisticidad no es ya sólo un atributo del lenguaje natural o de los lenguajes formales, sino que múltiples realidades no estrictamente verbales pueden considerarse lenguajes. Son comunes expresiones como "los lenguajes del arte", "los lenguajes de la música", "el lenguaje futbolístico", "el lenguaje de los sentimientos", "el lenguaje de la moda", "el lenguaje de la publicidad", "el lenguaje del espacio urbano" etc. Como si cualquier sector de lo real pudiera considerarse como soporte de un código significativo y estudiarse desde ese punto de vista.

Pero he preferido situar en el punto de partida, como un signo de nuestro tiempo, no la importancia de un hecho o de una serie de hechos, sino la experiencia de una inquietud: "una inquietud sobre el lenguaje - que no puede ser más que una inquietud del lenguaje y en el lenguaje mismo" (Derrida, 1967, p. 9). El signo de nuestro tiempo no es que el lenguaje se haya convertido finalmente en objeto de la ciencia y en tema para el pensamiento, ni siquiera que nuestro tiempo sea el tiempo del signo, el tiempo de la explosión de los signos y de la proliferación de los medios de comunicación. Todo eso son hechos de nuestro tiempo $\mathrm{y}$, sin duda, hechos muy importantes que afectan el mundo de la educación, tanto desde el punto de vista teórico como desde el punto de vista práctico. Pero al destacar los hechos olvidamos a veces de interrogar su sentido, como si el establecimiento de la verdad de lo que son las cosas nos permitiera despreocuparnos de considerar el sentido y el valor de lo que nos pasa. Y, a lo mejor, lo que (nos) ocurre es que el lenguaje ha dejado de ser seguro y de estar asegurado, ha dejado de ser nuestra propiedad o incluso nuestra casa. A lo mejor nuestra experiencia del lenguaje es la experiencia de la crisis del lenguaje y en nuestro lenguaje, la experiencia de la precariedad y la pluralidad de nuestro lenguaje, la experiencia del desfallecimiento de nuestro lenguaje que es, al mismo tiempo, la experiencia del desfallecimiento de los modos tradicionales de racionalidad que determinaban nuestro modo de conocer el mundo y de encarar la vida.

\section{La experiencia inquietante del lenguaje}

Es un hecho que nosotros "tenemos" lenguaje, que el hombre "posee" el lenguaje, que el hombre, como postula la enseñanza tradicional desde Aristóteles, es el ser viviente que habla. Es un hecho que el hombre tiene, entre otras, la "facultad" del lenguaje. Es un hecho que el lenguaje es algo real, algo que tenemos, una cosa que puede describirse y un instrumento que puede utilizarse. Es un hecho que el lenguaje es objeto de nuestro saber y materia prima para nuestras acciones. Expresar, comunicar, representar, insultar, prometer o persuadir son cosas que hacemos con el lenguaje. Es un hecho que podemos analizar el lenguaje, hablar sobre él, utilizarlo, controlarlo.

Pero lo que es inquietante es que el lenguaje no es una cosa entre las cosas, sino la condición de todas las cosas, el horizonte de todas las cosas, el lugar donde todas las cosas, incluyendo al hombre mismo y a ese lenguaje de la representación y de la comunicación que considera su propiedad, están como a distancia de sí mismas, como separadas de sí mismas. García Calvo lo dice con claridad cuando afirma que "el lenguaje está 
fuera y aparte de todas las cosas de las que él habla" (Garcia Calvo, 1989, p. 32), incluyendo desde luego al lenguaje mismo cuando es tratado como una cosa, cuando establece que "uno es el mundo en el que se habla y otro el mundo del que se habla" (Garcia Calvo, 1979, p. 339) o cuando observa que "siendo lenguaje lo que habla de (trata de, razona sobre, describe, explica y aún pregunta por) las cosas, cuando se vuelve sobre sí mismo se da un trance singular: en tanto que es él el que está hablando, no puede propiamente hablarse de él, y si se habla de él, es que ya no es aquél que estaba hablando" (Garcia Calvo, 1988, p. 187).

En la experiencia del lenguaje se produce una inquietante duplicación que no puede resolverse con el expediente de distinguir entre lenguaje-objeto y metalenguaje. Y no sólo porque sea condición de los lenguajes naturales el no poder quedar nunca cerrados como objetos determinados y, por tanto, el no poder quedar comprendidos en un metalenguaje que dé cuenta exhaustiva de todas sus condiciones. Esa duplicación es más bien una apertura absoluta por donde el lenguaje puede escaparse al infinito y en la que el sujeto del lenguaje (ese ser que tiene la facultad del lenguaje y que lo posee, lo utiliza y lo analiza como una cosa) se dispersa y se disuelve. Quizá la experiencia del lenguaje produzca no tanto una duplicación como una distancia, una distancia sin posibilidad de reflexión o de retorno, sin posibilidad de apropiación, en la que el lenguaje es pura exterioridad (que lo indetermina como comunicación o como representación) y en la que el sujeto del lenguaje no puede ya limitarlo ni controlarlo sino que queda emplazado e interpelado por ella.

Lo que es inquietante para la educación es que hablar y entender, escribir y leer no son sólo habilidades instrumentales. Por eso aprender lenguajes no es sólo adquirir herramientas para la expresión o para la comunicación. Lo que es inquietante es que el lenguaje no es sólo un sistema de signos utilizado para la representación de la realidad o para la expresión del sentido. Por eso el lenguaje no es sólo un objeto de enseñanza (entre otros objetos) ni un medio entre otros para la educación. La inquietud se produce cuando experimentamos que no están por un lado las cosas o los hechos y por otro las palabras que los nombran y los hacen comunicables, y aún por otro lado nosotros mismos entre las palabras y las cosas. La inquietud se produce cuando experimentamos que no siempre somos nosotros los que usamos el lenguaje o los que jugamos con el lenguaje, que el lenguaje no es solamente algo de nuestra propiedad.

Lo que es un hecho es la conciencia lingüística propia de nuestro tiempo, pero lo que es inquietante es el carácter linguiístico de la conciencia. Lo que es un hecho es la realidad del lenguaje, pero lo que es inquietante es el carácter lingüístico de la realidad. Lo que es un hecho es el pensamiento del lenguaje pero lo que es inquietante es el lenguaje del pensamiento (la inquietud no está en la filosofía del lenguaje sino en el lenguaje de la filosofía, no en las ciencia del lenguaje sino en el lenguaje de las ciencias), porque lo que es un hecho es que el lenguaje es un tema, aquello sobre lo que se piensa, aquello de lo que se habla, aquello de lo que se sabe, pero lo que es inquietante es que el pensamiento del lenguaje, y el habla del lenguaje y el saber del lenguaje también se producen en el lenguaje, por el lenguaje y como lenguaje.

$\mathrm{Y}$ en lo que sigue, para dibujar las condiciones de esa inquietud, algunos nombres: Nietzsche, Heidegger y Gadamer en la (así llamada) filosofía y Hofmannsthal y Handke en la (así llamada) literatura. Aunque no estaría de más decir, aunque sea de pasada, que uno de los efectos de la inquietud contemporánea sobre el lenguaje haya sido el hacerse borrosas las diferencias entre ambos tipos de discurso y el abrirse en el interior de cada uno de ellos y entre ellos de una pregunta insidiosa, obsesiva, imposible y sin respuesta: ¿qué es la filosofía? ¿qué es la literatura?

\section{Lenguaje, conocimiento y moral: N ietzsche}

El nombre de Nietzsche es fundamental en esa consideración del lenguaje como materia, como medio o como horizonte de toda vida mental, de toda vida social y de toda vida individual. Sin duda tiene razón Foucault cuando afirma que Nietzsche "inició la tarea filosófica de una reflexión radical sobre el lenguaje" (Foucault, 1979, p. 297). Y en el contexto de esa reflexión radical, Nietzsche inició también una problematización radical 
del lenguaje filosófico mismo no sólo temáticamente sino también en su propia escritura. Por eso, el nombre de Nietzsche es inevitable a la hora de exponer esa inquietud sobre el lenguaje y en el lenguaje en relación a la cual he querido situar estas páginas.

Puesto que las anotaciones de Nietzsche sobre el lenguaje son raras y dispersas, tomaré como principal referencia un hermosísimo texto de 1873 titulado "Sobre la verdad y la mentira en sentido extramoral" (Nietzsche, 1974, p. 85 e ss). En ese breve texto, no publicado en vida de Nietzsche, el autor construye una interpretación histórica del origen del hombre, de la verdad y del lenguaje que contiene algunas de sus mejores intuiciones antropológicas, epistemológicas y lingüísticas. Nietzsche comienza su exposición mostrando la arbitrariedad, la contingencia y la fugacidad de la aparición del hombre sobre la tierra. El hombre, ese animal inteligente que inventó el lenguaje y el conocimiento, constituye, en la naturaleza, "una excepción lamentable, vaga, fugitiva, inútil y arbitraria”. El lenguaje y el conocimiento son sólo humanos, demasiado humanos, meros instrumentos de supervivencia de un ser casual, y para nada trascendentes a la vida humana. El lenguaje y el conocimiento no son otra cosa que productos del instinto de conservación de ese animal débil y poco robusto que es el animal humano y expresiones de su vida sobre la tierra, de sus modos particulares de existencia. Lo que hay en el origen del lenguaje y del conocimiento es una especie de instinto ficcional, radicalmente perspectivista, orientado a la conservación de la vida y, más adelante, al poder. Porque a esa especie de necesidad biológica primera se añade después una suerte de obligación social derivada de que "el hombre quiere existir, por necesidad y aburrimiento a la vez, social y gregariamente" (idem, p. 87).

En este punto Nietzsche elabora la hipótesis de una especie de contrato social original o de primer tratado de paz orientado a la constitución del grupo y a garantizar su mantenimiento. Y como condición de este impulso gregario que lleva a los hombres a constituirse en sociedad "se fija lo que en adelante debe ser 'verdad', es decir, una designación de las cosas uniformemente válida y obligatoria" de la que surge por primera vez "el contraste entre verdad y mentira" (idem, p. 88).
La hipótesis nietzscheana establece la conexión entre lenguaje, conocimiento y humanización, entendiendo por humanización el resultado de un impulso social y moral dictado por el instinto de conservación, por el miedo a la incertidumbre y por la voluntad de dominio. El concepto como designación normativa, la verdad como juicio obligatorio y el lenguaje mismo como conjunto de reglas semánticas y sintácticas orientadas a la representación convencional de la realidad no son otra cosa que productos sociales y morales tan arbitrarios, tan contingentes y tan fugaces como el tipo de vida que producen y que aseguran. El lenguaje no es lógico ni representativo, nada garantiza la necesidad de su estructura ni su conexión con el mundo, con la realidad o con las cosas. Y a partir de ese lenguaje natural concebido como una fuerza plástica original, libre y arbitraria, los hombres han ido fabricando poco a poco conceptos, juicios y verdades y han ido configurando con ellos un lenguaje apto para la filosofía, para la ciencia, para la comunicación y, en general, para los negocios de la vida. Para Nietzsche, y en esto realiza la primera crítica filosófica radical del lenguaje, los conceptos no son otra cosa que metáforas fijadas y anquilosadas, las verdades no son sino las ficciones que se imponen como dominantes y las reglas del lenguaje funcionan como garantía del orden social:

Por tanto, ¿qué es la verdad? Una multitud en movimiento de metáforas, metonimias, antropomorfismos; en una palabra, un conjunto de relaciones humanas que, elevadas, traspuestas y adornadas poética y retóricamente, tras largo uso el pueblo considera firmes, canónicas, vinculantes: las verdades son ilusiones de las que se ha olvidado que lo son, metáforas ya utilizadas que han perdido su fuerza sensible, monedas que han perdido su imagen y que ahora entran en consideración como metal, no como tales monedas (idem, p. 91).

Sin embargo ese libre poetizar constitutivo del lenguaje no es sólo una especie de libertad originaria definitivamente perdida y cancelada, sino también una posibilidad que permanece latente en el interior del lenguaje y que lo abre siempre a una especie de transgresión permanente. Para Nietzsche

[...] este instinto que impulsa a la formación de metáforas, este instinto fundamental del hombre, del que en ningún momento 
se puede prescindir, porque en tal caso se habría prescindido del hombre mismo, en realidad no ha sido sometido ni prácticamente dominado por habérsele construído un mundo regular y rígido como una fortaleza con sus productos volatilizados, los conceptos (idem, p. 98).

El espíritu servil es temeroso y por eso busca crencias, seguridades, consensos, convenciones. Pero todo eso a lo que

[...] se agarra el hombre menesteroso para salvarse, representa para el intelecto liberado una mera armadura y un juego para sus obras de arte más temerarias, y cuando lo deshace, confunde sus elementos, los recompone irónicamente emparejando las piezas dispares y separando las más similares, descubre que no necesita el expediente de la indigencia (idem, p. 99).

La magnífica intuición nietzscheana es que el orden del lenguaje, el orden epistemológico y el orden moral son solidarios. Por eso el que utiliza la lengua de otro modo no sólo se revela contra la lengua, sino contra las formas impuestas de la verdad y contra el orden social; el que ve las cosas de otro modo no sólo se revela contra la ciencia, sino también contra las formas lingüísticas convencionales y contra la moral dominante; y el que trata de vivir de forma distinta a las formas de vida que se nos dan como normales no sólo se revela contra la sociedad, sino contra el saber y contra el lenguaje. En el orden del lenguaje se juega cómo nombramos lo que vemos y cómo vemos lo que nombramos, cómo ponemos juntas las palabras y las cosas, cómo normativizamos o des-normativizamos nuestro modo de dar un sentido al mundo y a nosotros mismos, en suma cómo pensamos, cómo actuamos y cómo vivimos.

Por otra parte, la reflexión nietzscheana sobre el lenguaje implica una crítica radical a la ontología que mantiene la fe en la existencia del mundo, de las cosas, de la realidad, de los fenómenos o, simplemente, del ser, independientemente de las formas del lenguaje, de las formas del conocimiento y de las formas de vida. Si Nietzsche substituye el concepto de "Ser" por el de "Vida", si sustituye la "Ontología" por la "Psicología", es para indicar que el ser no es más que interpretación puesto que vivir es evaluar. Por eso la "Psicología" de Nietzsche no tiene nada que ver con el biologismo ni con el psicologismo sino que es a la vez filológica y médica, una especie de arte del desciframiento de las interpretaciones en tanto que síntomas de "salud" o de "enfermedad", es decir de afirmación o de negación de la vida. El desciframiento de las interpretaciones no es la determinación de su verdad, sino de su valor, es decir, de la nobleza o de la bajeza de la voluntad que interpreta, de su intención inconsciente. El problema no es el de la verdad de las interpretaciones, sino el de su valor. El problema es el valor de la verdad para la vida, para un cierto tipo de vida.

La hipótesis nietzscheana es que nuestra visión de la realidad está siempre condicionada por prejuicios y estructuras mentales que tienen una historia lingüística y social. Pero eso no quiere decir sólo que al aprehender la realidad no podamos prescindir de nuestros prejuicios, de nuestros conceptos, de nuestras palabras, sino que la realidad sólo se constituye como tal en un mundo lingüístico e interpretativo. Lo real se da interpretado, la realidad es lingüística. En el parágrafo 374 de La Gaya Ciencia Nietzsche escribe: “... el mundo se ha vuelto por segunda vez infinito para nosotros, por cuanto no podemos refutar la posibilidad de que sea susceptible de interpretaciones infinitas. Otra vez sentimos el gran escalofrío" (Nietzsche, 1979, p. 237). El mundo, el ser, se nos ha vuelto infinito porque nos aparece como texto, es decir, como algo a ser leído, a ser interpretado. Todo lo que aparece a la conciencia es interpretación, lectura, signo. En la experiencia que hacemos del mundo sólo leemos textos sin que nunca podamos llegar a un referente último que sea previo a la interpretación. Por eso la tesis de Nietzsche no significa sólo que el mundo sea un texto "susceptible" de interpretaciones infinitas, de lecturas infinitas, sino que el mundo mismo es ya una interpretación, una lectura. No hay "texto original" o un "texto absoluto" independientemente de sus interpretaciones y al cual podamos referirnos para juzgar la verdad de esas mismas interpretaciones. Anticipándose de cierta forma a la visión del ser propia de la ontología hermenéutica contemporánea cuyas raíces están en el segundo Heidegger, la posición nietzscheana podría resumirse diciendo que todo el ser es interpretación o, de otro modo, que el ser sólo acontece como interpretación. 


\section{Ser y lenguaje: Heidegger}

En una serie de conferencias pronunciadas en la Universidad de Friburgo en diciembre de 1957 y febrero de 1958 tituladas La esencia del habla (Heidegger, 1957-1958, p. 141-194) Heidegger toma como motivo un verso de Stefan George que dice así: ninguna cosa sea donde falta la palabra. A través de una cuidadosa reflexión que toma como punto de partida lo que sean las palabras, lo que sean las cosas y lo que sean los nombres como un tipo de palabras que mantienen una relación particular con las cosas, Heidegger va ampliando y transformando el significado del verso hasta hacerle portador de otro y del mismo sentido: "un es se da donde se rompe la palabra".

En un primer movimiento, Heidegger interpreta la frase de George como una enunciación de que es la palabra y esencialmente el nombre el que confiere el ser a la cosa: "el ser de cada cosa que es reside en la palabra. De ahí la validez de la frase: el lenguaje es la casa del ser" (idem, p. 149). Desde ese punto de vista, la relación entre las palabras y las cosas no es una conexión entre "cosa" de un lado y "palabra" de otro, sino que es la palabra la que funda la relación, es decir, que "la palabra misma es la relación que en cada instancia retiene en sí la cosa de tal modo que 'es' una cosa" (idem, p. 152). La palabra y esencialmente el nombre no es un significante que se superpone a un significado, tampoco es un medio de re-presentación entendido como un traer presente lo que está ya de antemano como una cosa ante nosotros, sino que es la palabra la que hace venir a la presencia a las cosas. Y ese hacer venir a la presencia es justamente una donación de ser, la donación de las condiciones en las que algo puede aparecer como lo que es.

La hipótesis ontológica de Heidegger, aquella según la cual es la palabra la que confiere el ser a la cosa, es hasta aquí coherente con la ontología hermenéutica según la cual no hay un darse del ser fuera del lenguaje. Desde ese punto de vista, el lenguaje es fuente del ser en el sentido en que deja aparecer las cosas en tanto cosas que son y las deja estar presentes. Heidegger enuncia esta hipótesis ontológica en sus glosas del verso de George, por ejemplo:
'Cosa' denominaba aquí cualquier ente que de algún modo está presente. Por lo demás, decíamos acerca de la 'palabra' que no sólo se hallaba en una relación con la cosa, sino que la palabra es lo que primero lleva esta cosa, en tanto que ente, a este 'es'; que la palabra es lo que la mantiene allí, la sostiene y, por así decirlo, la provee del sustento para ser cosa" (idem, p. 167); y, en otro lugar: “... 'ninguna cosa sea donde falta la palabra' apunta hacia la relación entre palabra y cosa, de tal modo que la palabra misma es la relación en tanto que sostiene toda cosa hacia su ser y la mantiene en él. Sin la palabra que de este modo retiene la totalidad de las cosas, el 'mundo' se hundiría en la oscuridad incluyendo al "yo"” (idem, p. 158).

El mundo está iluminado y no está hundido en la oscuridad porque hay palavra.

$Y$ el ser humano como ser-en-el-mundo, como insertado en ese mundo iluminado y sostenido en su ser por la palabra, obtiene también su condición de posibilidad por esa palabra misma que es "casa del ser". El lenguaje no es (sólo) algo mundano sino condición del mundo, y no es (sólo) propiedad del yo sino condición suya. Por otra parte, y dada la historicidad y la pluralidad del lenguaje, su dimensión ontológica consiste en su capacidad para abrir no el mundo sino un mundo, y para posibilitar no el yo sino un yo, un determinado modo de subjetividad histórica y culturalmente determinado.

Hasta aquí la posición heideggeriana es claramente coherente con el análisis de la obra de arte como "puesta en obra de la verdad" (1958) porque la verdad no es ya correspondencia de la proposición con la realidad (y, por lo tanto, conexión entre la palabra y la cosa) sino, más fundamentalmente, el abrirse de horizontes de sentido en el interior de los cuales es posible la verificación de proposiciones. También es coherente con el motivo hölderliniano reiteradamente usado por Heidegger, ese de "lo que permanece lo fundan los poetas" (1989), en el sentido de que el lenguaje poético (como lenguaje originario) configura la familiaridad originaria con el mundo que constituye la condición de la experiencia.

Pero más adelante, al final de la segunda conferencia sobre "La esencia del habla", Heidegger abre una interrogación distinta: no ya por la relación entre la palabra y la cosa o por el modo como la palabra da (o funda, o alberga, o sostiene) el ser de la cosa, sino por el 
ser mismo de la palabra. El punto de partida de la argumentación es que si la palabra es, ella también debe ser una cosa, puesto que "cosa" designa todo aquello que de algún modo es. Nos encontraríamos entonces en la situación de que una cosa, la palabra, es la que le da el ser a otra cosa, el objeto. Para el sentido común, en efecto, el lenguaje es una cosa entre las cosas: las palabras se ven y se oyen, se eligen y se utilizan, se pueden clasificar, ordenar, analizar, componer y descomponer. Pero lo inquietante es que cuando es el lenguaje el que habla (y no aquello de lo que se habla) el lenguaje no es una cosa. Heidegger lo dice nítidamente: “... la palabra, que no es en sí misma cosa alguna, ningún algo que 'es', se nos escapa" (idem, p. 171) o un poco más adelante, aún más claramente: “... la palabra, el decir, no tiene ser” (idem p. 172).

Esa misma duplicación entre una palabra que es una cosa y una palabra que, sin ser una cosa, confiere el ser a las cosas (al mundo, al yo, al lenguaje mismo en tanto que cosa que tenemos y que utilizamos) está enunciada en otro lugar desde la distinción entre lo dado y lo que da:

Si pensamos rectamente, nunca podremos decir de la palabra: ella es, sino: ella da, no en el sentido de que 'se den' palabras, sino en cuanto sea la palabra misma la que da. La palabra: la donante. ¿De qué hace don? De acuerdo con la experiencia poética y según la más antigua tradición del pensamiento, la palabra da: el ser. Entonces, pensando, deberíamos buscar en el 'ella, que da' la palabra como la donante misma, sin estar ella jamás dada (idem p. 173).

El lenguaje "es" cuando hablamos de él, cuando está dado, cuando nos lo podemos representar como algo existente, cuando lo podemos utilizar como algo que es como un instrumento de nuestra propiedad. Pero cuando el lenguaje habla, ese lenguaje que habla se nos desliza, se nos niega, se nos disuelve, se nos hace misterioso y nos inquieta. Cuando es el lenguaje el que habla no somos nosotros los que tenemos al lenguaje, sino que es el lenguaje el que nos tiene a nosotros. Por eso "... el habla no es simplemente una capacidad del ser humano" (idem, p. 192). Y el lenguaje no es ya lo pensado, sino lo que da que pensar.

Se produce pues en el lenguaje una suerte de duplicación según lo consideremos como una cosa (o como una facultad) o como una condición del ser de las cosas que, como tal condición, no es cosa alguna, no está dado o no tiene ser. Se produce pues una especie de doblete empírico-trascendental en el que la dimensión trascendental del lenguaje (entendiendo "trascendental" en sentido kantiano, como condición de posibilidad de la experiencia) no es a-priori y necesaria sino radicalmente histórica, finita y contingente. El lenguaje constituye un horizonte histórico finito, nunca completamente cognoscible y determinable excepto como tal horizonte, y por eso puede hablarse de un "acontecer" de la verdad o del ser como "evento". Por eso, como indica Heidegger como de pasada abriendo su texto hacia senderos desconocidos que serán transitados por heideggerianos heterodoxos como Derrida, "un fulgor repentino ilumina la relación entre muerte y habla pero está todavía sin pensar" (idem, p. 193).

Y ahora ya estamos en condiciones de dar sentido a la modificación que Heidegger propone en el verso de George, esa que traduce "ninguna cosa sea donde falta la palabra" por "un es se da donde se rompe la palabra". El romperse de la palabra no significa aquí en absoluto un quebrantamiento del lenguaje que nos conduciría, al modo fenomenológico, directamente a las cosas mismas en su evidencia objetiva, inmediata y prelingüística. El romperse de la palabra es aquí una suerte de desfallecimiento al que toda palabra como palabra ya dicha está destinada. O, dicho de otro modo, el romperse de la palabra alude a la constitutiva finitud de todo decir constituído, de toda relación representativa entre palabras y cosas, de todo horizonte dado de experiencia. El fulgor del nexo entre lenguaje y mortalidad no puede ser otra cosa que la intuición de la mortalidad propia del ser en tanto que dicha mortalidad está ya anunciada en la finitud propia del lenguaje: "Romper quiere decir aquí: la palabra resonante regresa a lo insonoro, allá desde donde ella es concebida: al son del silencio" (idem, p. 194).

\section{O ntología hermenéutica o lingüisticidad del ser: Gadamer}

Lo que hoy se llama "ontología hermenéutica" suele remitirse a la obra que Gadamer publicó en 1960 con el título de Verdad y Método (Gadamer, 1960). El 
problema de ese libro, como el mismo Gadamer establece en el título de la larga sección introductoria, es "el problema de la verdad sobre la base de la experiencia del arte". Desde ese punto de vista, y más allá de la cuestión restringida de la comprensión como método propio de las ciencias humanas, Gadamer generaliza la comprensión como constituyente del modo humano de ser-en-el-mundo y opera un giro ontológico en dirección al ser que es medio, objeto y sujeto de la comprensión, es decir, el lenguaje. Con ello la hermenéutica gadameriana se extiende hasta incluir en su ámbito la ciencia y la técnica e incluso la totalidad de la experiencia humana. Y tal es la tesis desarrollada especialmente en la sección final de la obra, la que se titula El lenguaje como horizonte de una ontología hermenéutica (idem, p. 526 e ss), que constituirá la base de mi exposición.

La tesis fundamental de Gadamer es que la hermenéutica, en tanto que impulsada por una exigencia de universalidad, concierne a la totalidad de nuestro acceso al mundo mientras que el lenguaje y su forma de realización (el diálogo) soporta no sólo la representación de las cosas o la comunicación entre los hombres sino también la aparición de las cosas que constituyen el mundo y la posibilidad misma de los hombres como seres-en-el-mundo.

Tomando como punto de partida las implicaciones filosóficas (y no etnológicas o psicológicas) de los análisis de Humboldt sobre la diversidad y la relatividad de los lenguajes naturales y sobre el modo como cada uno de ellos determina formas distintas de pensamiento, Gadamer enfatiza las posibilidades antropológicas de la tesis genética de Humboldt de que el lenguaje es humano desde su comienzo. Y la glosa del siguiente modo:

El lenguaje no es sólo una de las dotaciones de que está pertrechado el hombre tal como está en el mundo, sino que en él se basa y se representa el que los hombres simplemente tengan mundo. Para el hombre el mundo está ahí como mundo, en una forma bajo la cual no tiene existencia para ningún otro ser vivo puesto en él. Y esta existencia del mundo está constituída lingüísticamente [...]. La humanidad originaria del lenguaje significa, pues, al mismo tiempo, la lingüisticidad originaria del estar-en-el-mundo del hombre (idem, p. 531).
Para la hermenéutica entendida ontológicamente el lenguaje no sólo es un sistema convencional de signos para la representación de la realidad o para la expresión de la subjetividad, que ni siquiera constituye un instrumento para la comunicación, sino que constituye el modo primario y original de experimentar el mundo. Y es desde ese punto de vista que debe leerse la célebre sentencia de Gadamer: "El ser, que puede ser comprendido, es lenguaje" (idem, p. 567). Como apunta Vattimo "el enunciado debe leerse con las dos comas, las cuales, al menos en castellano, excluyen todo significado restrictivo, que sería además simplemente tautológico: no es (sólo) ese ser que es objeto de 'comprensión' (por ejemplo, en oposición a 'explicación causal' etc.) que es lenguaje, sino que es todo el ser que, en cuanto puede ser comprendido, se identifica con el lenguaje" (Vattimo, 1989, p. 85-86). La ontología hermenéutica pretende validez universal y eso significa que en y por el lenguaje se nos revela el ser en todas sus modalidades. La tesis fundamental de la ontología hermenéutica es la lingüisticidad del ser.

Para la ontología hermenéutica, y en esto sigue a Heidegger, el lenguaje es el modo de aparición del ser. Por otra parte, y en la estela de Nietzsche, la ontología hermenéutica disuelve el principio objetivista de la realidad y la teoría positiva de la verdad como correspondencia: no hay hechos, sólo interpretaciones o, dicho de otra manera, el mundo verdadero se convierte en fábula. $\mathrm{La}$ verdad no se entiende desde el modelo positivo del saber científico como correspondencia de las proposiciones y los hechos, la realidad no se entiende como lo que está más allá del lenguaje, y el lenguaje mismo no puede quedar determinado como mero medio de significación y de comunicación. Partiendo de la experiencia del arte y, en general, del modelo de la retórica, Gadamer ofrece una concepción no instrumental del lenguaje, una concepción no objetivista de la realidad y una concepción no metafísica de la verdad cuyas implicaciones educativas desarrolla abundantemente a lo largo de su obra.

\section{La tentación del silencio: $\mathrm{H}$ ofmannsthal}

La inquietud del lenguaje se manifiesta también como crítica del lenguaje siempre que tengamos en cuenta 
la relación constitutiva entre crítica y crisis. La inquietud del lenguaje es la crisis del lenguaje, la experiencia de un lenguaje atravesado por la crisis, habitado por la crisis, por una crisis que arrastra consigo al mundo que el lenguaje pretendía representar y ordenar y al individuo como sujeto poseedor y administrador del lenguaje.

La inquietud de la crisis del lenguaje se expresa de una forma radical en una obra de poco más de diez páginas en la edición española del escritor vienés Hugo von Hofmannsthal. La obra, escrita entre 1901 y 1902, se titula Carta de Lord Chandos (Hofmannsthal, 1996) y es considerada no sólo como uno de los documentos programáticos más vigorosos del expresionismo literario sino también como el texto fundacional de la Sprachkritik que se desarrolló en Austria a comienzos de este siglo. La Carta constituye un testimonio de la enfermedad de las palabras y de la imposibilidad de los juicios, del desfallecimiento del lenguaje y, por lo tanto, del naufragio del yo y de la pérdida del mundo. El autor de la carta comunica a su corresponsal su decisión de abandonar la vocación y la profesión de escritor y las razones que le han conducido a esa decisión, simplemente la pérdida de "la capacidad de pensar o hablar coherentemente sobre cualquier cosa". Chandos no puede usar las palabras comunes, aquellas que todo el mundo usa, sin sentir un inexplicable malestar, sin tener la sensación de que se le "descomponían en la boca como hongos podridos" (idem, p. 30). Además se siente impotente para juzgar puesto que los juicios comunes le parecen vacuos y falsos. Y siente la imposibilidad de expresar sus pensamientos o sus sensaciones. Chandos se ha quedado mudo porque el lenguaje no es capaz de contener o de ordenar el mundo. Lo que se le ha arruinado es la "imagen simplificadora de la costumbre" (idem, p. 31), la mirada del hábito. La antigua casa del lenguaje se le ha hecho inhabitable y aún no dispone de un lenguaje que le permita expresar lo vivido. Por eso el lenguaje está en crisis, porque se nos ha hecho falso y caduco el lenguaje de la racionalidad clásica y aún no disponemos de una nueva racionalidad que esté a la altura de la complejidad de nuestra época.

\section{La mecanizacción del lenguaje: Handke}

En la estela de la Sprachkritik de principios de siglo se sitúa el llamado "grupo de Viena" y, posteriormente, el llamado "grupo de Graz" en el que el escritor austríaco Peter Handke veló sus primeras armas literarias. Para Peter Handke el lenguaje convencional propio de la era de la comunicación, ese lenguaje lleno de clichés y de frases hechas, ese lenguaje oído a diario y que ya no dice nada, ese lenguaje no nos deja ver ni hablar, porque nos lo da todo visto y nombrado. El lenguaje de nuestro mundo es palabrería, cháchara insustancial, una especie de rejilla convencional y falsa que nos impide ver, que nos impide expresarnos y que nos impide la comunicación. Uno de los problemas que habita la escritura de Handke es el de la mecanización de lo que se dice. En un artículo de 1973 titulado “¿Qué puedo responder a eso?" Handke muestra su malestar frente a esas opiniones personales que son siempre completamente impersonales, frente a esas convenciones de la opinión que nos dan la realidad ya dicha y ya interpretada de antemano: "Hace unos cuantos días alguien me llamó por teléfono y me preguntó: ¿qué opinas sobre el alto el fuego en Vietnam? Yo no contesté, me limité sólo a decir algunas palabrotas y hablé de otra cosa. Lo que había que decir no habría sido mío, y yo me siento especialmente extraño a mí mismo siempre que se me hace decir algo que una máquina hubiera podido escupir exactamente igual que yo" (Handke, 1978, p. 27). Esa misma máquina de hablar aparece cuatro años más tarde en una de las anotaciones de El peso del mundo: "Inventar una máquina para que uno no tenga que hablar (una máquina que uno acciona cuando le hablan y que contesta por uno)" (Handke, 1981, p. 34). O la pregunta obsesiva de La historia del lápiz: "A cada frase que pase por tu cabeza pregúntate: ¿realmente ésta es mi lengua?" (Handke, 1991, p. 50).

Y para introducir el problema de la mecanización del lenguaje en una obra planteada en un contexto implícitamente educativo, baste la referencia a una obra de teatro de 1968 titulada Gaspar, escrita sobre la historia de un misterioso muchacho de unos dieciséis años aparecido en una plaza de Nüremberg en 1828 y que, como indica el mismo Handke en las primeras acotaciones sobre la puesta en escena, podría haberse titulado también "tortura verbal". La obra "muestra lo que es posible hacer con alguien [...] cómo se puede hacer hablar a alguien hablándole" (Handke, 1982, p. 11), el modo 
lento e implacable, puramente linguiístico, como unos "apuntadores" enseñan a hablar a Gaspar introduciéndole al mismo tiempo en la cárcel del lenguaje y en la cárcel del sistema, en la jaula de los modos habituales de percepción, de expresión y de comportamiento en los que los seres humanos normales han sido instruidos y encerrados. A continuación de una primera frase pronunciada por Gaspar "sin tener idea de lo que dice, sin expresar otra idea que la de no tener idea de la frase que dice" (idem, p. 18), como lanzándose a hablar sin hablar aún propiamente, como indicando sólo que ya ha empezado a hablar, los apuntadores empiezan a hablar desde todos los lados "sin recurrir a los medios habituales de expresión de lo irónico, del humor, de la camaradería, del calor humano [...] hablan de forma inteligible. Hablan, a través de una buena instalación microfónica, un texto que no es el suyo" (idem, p. 20).

Y poco a poco, apuntando a Gaspar tanto lo que debe decir como el significado de lo que dice, van montando todo un orden tranquilo y tranquilizador hecho de creencias comunes, de frases comunes, de sentimientos comunes, de comportamientos comunes. Justo antes del intermedio, cuando el trabajo de los apuntadores ya ha constituído un yo estable y un mundo ordenado mediante el único recurso del lenguaje, Gaspar ya puede pronunciar el siguiente monólogo:

Soy sano y fuerte. Soy educado y honesto. Soy consciente de mis responsabilidades. Soy trabajador, discreto y sencillo. Soy siempre amable. No tengo grandes ambiciones. Soy por naturaleza simpático y normal. Todo el mundo me quiere. Puedo resolver cualquier problema. Estoy al servicio de todos. Mi sentido del orden y de la limpieza no dan lugar a reproche alguno. Mis conocimientos están por encima del nivel medio. Ejecuto cualquier trabajo que se me confía a plena satisfacción. Cualquiera puede dar de mí los mejores informes. Soy íntegro y pacífico. No soy de esos que por cualquier pequeñez ponen el grito en el cielo. Soy tranquilo, sensible y consciente de mi deber. Me entusiasmo por cualquier buena causa. Quisiera abrirme camino. Quisiera aprender. Quisiera hacerme útil. Tengo nociones de longitud, anchura y profundidad. Trato los objetos con delicadeza. Me he acostumbrado ya a todo. Me va bien. Ya puedo afrontar la muerte. Ahora mi mente está clara. Ya pueden dejarme solo. Me gustaría mostrarme siempre bajo mi mejor aspecto. No acuso a nadie. Me río mucho. Para mí todo rima. No tengo señas particulares. No enseño, al reir, la encía superior. No tengo ninguna cicatriz bajo el ojo izquierdo, ni ningún lunar tras la oreja derecha. No soy un peligro público. Quisiera ser un hombre activo. Quisiera colaborar. Estoy orgulloso de lo alcanzado. Tengo por ahora mis necesidades cubiertas. Puedo prestar declaración. Ante mí se abre un nuevo camino. He aquí mi mano derecha. He aquí mi mano izquierda. Si es necesario puedo esconderme en los muebles. Siempre fue mi deseo estar con ustedes. Ahora sé lo que quiero: quiero estar tranquilo. Y cada objeto que me inquieta lo hago mío para que deje de inquietarme. (idem, p. 64).

Durante el intermedio se oyen voces en off de líderes políticos, de Papas, de oradores, de primeros ministros y jefes de gobierno, de periodistas, de poetas, de todos aquellos apuntadores que, hablándonos desde todos los lados, nos enseñan a hablar como está mandado, a decir lo que todo el mundo dice, a creer lo que todo el mundo cree, a ver las evidencias, a pensar lo que todo el mundo piensa, a opinar, mientras las voces van siendo ahogadas por ruidos de campanas, sirenas de fábrica, tableteos de máquinas de escribir, risas de mujeres en una reunión social, gritos de espectadores en un partido de fútbol, frenazos de coches, pitidos y órdenes. Y en la segunda parte ya los apuntadores aparecen como Gaspares y ya Gaspar se ha convertido en un apuntador que empieza a recitar su historia, hablando ya como los otros apuntadores y jaleado por ellos, hasta su final previsible: "Me han hecho hablar. Me han trasladado a la realidad. ¿Oís? (Silencio)” (idem, p. 84).

Handke muestra constantemente en su escritura la insatisfacción con el lenguaje recibido, la crítica constante de los clichés, la búsqueda minuciosa y casi maniática de un lenguaje en el que las cosas puedan aparecer en su pureza, el enorme esfuerzo que se requiere para que las cosas, incluso las más banales, las más cotidianas, las más simples, no se nos den ya falsificadas por esos esquemas fosilizados de percepción que, justamente por ser convencionales, nos dan una falsa sensación de realidad. La escritura de Handke atiende a lo aún no descrito, a experiencias aún no registradas, a formas aún inéditas que tiemblan en las grietas de silencio que se abren a veces en el súbito apartarse de un lenguaje que se ha vuelto hostil e inexpresivo. 
Gran parte de la escritura contemporánea (literaria, pero también filosófica) se mueve entre la tentación del silencio y la revuelta lingüística. La escritura como el intento interminable y casi desesperado de construir un lenguaje que sea capaz de romper la charlatanería ambiente y de darnos una experiencia más limpia de las cosas.

\section{La inquietud del lenguaje y la educación: algunassugerencias}

\author{
Sólo puedo amar a aquellos que poseen un lenguaje \\ inseguro; y quiero hacer inseguro el lenguaje de aquellos \\ que me agradan.
}

Peter Handke

Hannah Arendt dice que la esencia de la educación es la natalidad, el hecho de que constantemente nacen seres humanos en el mundo. Por eso lo que está en juego en la educación es nuestro modo de recibir a los nuevos. En el horizonte del lenguaje, la educación es el proceso por el que los recién llegados, que no hablan, son introducidos en el lenguaje. Desde ese punto de vista, la educación implica una responsabilidad para con el lenguaje puesto que el lenguaje es ese don que nosotros hemos recibido y que tenemos que transmitir. E implica también una responsabilidad con los nuevos, es decir con esos seres humanos que, en el lenguaje de todos, tienen que tomar la palabra, su propia palabra, esa palabra que es palabra futura e inaudita, palabra aún no dicha, palabra del por-venir. Introducir a los nuevos en el lenguaje es, por tanto, hablar y hacer hablar, hablar y dejar hablar.

Lo que se transmite no es sólo el lenguaje, sino nuestra relación con el lenguaje. Por ejemplo, nuestro amor al lenguaje, nuestra desconfianza hacia el lenguaje, nuestra atención al lenguaje, nuestro respeto por el lenguaje, nuestra delicadeza con el lenguaje, nuestro descuido con el lenguaje, nuestra manera de escuchar el lenguaje.

Al entrar en el lenguaje y, sobre todo, en el lenguaje escrito, en el texto, los nuevos son situados en lo que viene diciéndose, en ese venir presente en la lectura de lo que ya se dijo pero que, en cuanto texto leído, viene diciéndose cada vez de nuevo. Otra vez lo mismo, pero de nuevo, en una repetición que es diferencia. Pero aprender a leer no es sólo adquirir la capacidad de entender lo que el texto dice, sino ser capaces de escuchar, en lo dicho, lo que da-que-decir, lo que queda por decir. Por eso la acción de leer desborda el texto y en virtud de la disposición en lo que diciéndose viene el lector se encamina al porvenir del decir.

Introducir a los nuevos en el lenguaje se limita, en demasiadas ocasiones, a hacer hablar como está mandado, a decir lo que todo el mundo dice, a pensar lo que todo el mundo piensa. Pero permitir que los nuevos tomen la palabra implica la ruptura de lo dicho, la distancia respecto al lo que se dice y la transgresión de las reglas del decir. Sólo esa ruptura, esa distancia y esa transgresión dejan que el lenguaje hable, dejan hablar.

Podemos enseñar la lengua que sabemos, que tenemos, que utilizamos. Podemos transmitir la lengua que nos pertenece. Pero el lenguaje que habla y al que nosotros pertenecemos no es un ente, una cosa entre las cosas, sino el horizonte de todas las cosas. Y, como tal horizonte, no puede ser objeto de nuestro saber (hablar) ni instrumento de nuestro poder (de hablar). Si ese lenguaje no es una cosa, tiene que ser algo que no puede ser comprendido teóricamente ni dominado prácticamente, tiene que ser algo que no puede depender de nosotros como sujetos y que, por lo tanto, no puede ser transmitido por nosotros como sujetos, ni desde nuestro saber (hablar) ni desde nuestro poder (de hablar). Lo único que puede transmitirse, entonces, es la atención al lenguaje. Y ahí, en la atención, no es el individuo en tanto que sujeto el que entra en relación con el lenguaje, sino que sólo puede atender en tanto que se libera de su ser sujeto, de su saber (hablar), de su poder (de hablar), de su voluntad (de decir lo que quiere). El lenguaje aparece como algo a lo que podemos atender pero no como algo que podamos tener o poseer, no como algo de lo que podamos apropiarnos.

Sin embargo, el lenguaje es lo que nos es más cercano, más íntimo. José Luis Pardo (1996) distingue entre la experiencia intimidatoria y la experiencia íntima del lenguaje. En la experiencia intimidatoria, el 
lenguaje remite al significado público y convencional de las palabras, a su univocidad, su precisión, su rectitud o su impersonalidad independientemente de quién las diga, las escuche, las escriba o las lea. Se trata de un lenguaje puramente inteligible, sin calor, como el de los apuntadores de Gaspar. En la experiencia íntima del lenguaje, por el contrario, el lenguaje muestra su cara interna, el modo como le suena o le resuena o le sabe a cada uno. Y en ella uno es capaz de decir lo que no sabe decir o lo que no quiere decir. Y en la experiencia íntima del lenguaje, el lenguaje no es nunca plenamente propio, no es nunca propiedad, porque igual que vivir la vida es desvivirse por lo que no se puede tener, hablar la lengua íntima es tomar una palabra que nunca se podrá poseer completamente, una palabra imprevista e imprevisible que sólo viene o adviene cuando uno se abandona a la palabra y se abre, con ella, a lo nuevo del hablar. El lenguaje íntimo no es el más propio, sino el más ajeno, el más impropio, el que siendo más cercano es a la vez el más lejano.

El lenguaje que se puede transmitir es el de la experiencia intimidatoria del lenguaje, pero al de la experiencia íntima sólo puede iniciarse íntimamente, es decir, con todos los balbuceos, las alusiones, las dudas, las dificultades, los temblores de voz, los tonos y los silencios que palpitan en un lenguaje inseguro, inquieto, siempre a punto de quebrarse, de desfallecer.

Para que el lenguaje recupere su intimidad perdida o, simplemente, para que el lenguaje por fin hable es necesario primero quebrar ese lenguaje seguro y asegurado de los que saben lo que dicen, de los que hablan arrogantemente, de los que hablan como está mandado y dicen lo que todo el mundo dice, de esos a los que se les puede escuchar y obedecer pero a los que no se puede amar. Por eso "sólo puedo amar a aquellos que poseen un lenguaje inseguro; y quiero hacer inseguro el lenguaje de aquellos que me agradan" (Handke, 1991, p. 90).

JORGE LARROSA é doutor em Pedagogia pela Universidade de Barcelona - Espanha, onde atualmente é professor titular de Filosofia da Educação. Publicou diversos artigos e em periódicos brasileiros e dois livros: Imagens do outro (Vozes, 1998) e Pedagogia profana (Autêntica, 1999).

\section{Referencias Bibliograficas}

ARENDT, Hannah, (1966). "La crisis en la educación”. In: Entre el pasado y el futuro. Barcelona: Península.

DERRIDA, Jacques, (1967). L'écriture et la différence. Paris : Seuil. FOUCAULT, Michel (1979). Las palabras y las cosas. Madrid : Siglo XXI. Onceava edición ( $1^{\mathrm{a}}$ ed. em 1966).

GADAMER, Hans-Georg (1960). Verdad y Método. Salamanca : Sígueme.

GARCIA CALVO, Agustín, (1989). Hablando de lo que habla. Estudios de lenguaje. Madrid: Lucina. , (1979). Del lenguaje. Madrid : Lucina.

(1988). “Lenguaje” en REYES, Román (director) Diccionario de Terminología Científico-social. Barcelona : Anthropos.

HANDKE, Peter, (1982). Gaspar. Madrid: Alianza (1ª ed. em 1968). , (1978) “Qué puedo responder a eso?” en Cuando desear todavía era útil. Barcelona :Tusquets ( $1^{\mathrm{a}} \mathrm{ed}$. em 1973). , (1981) El peso del mundo. Barcelona : Laia (1 ${ }^{\mathrm{a}}$ ed. em 1975-77).

, (1991) Historia del lápiz. Barcelona : Península (1ª ed. em 1982).

HEIDEGGER, M (1987). De camino al habla. Barcelona : Serbal ( $1^{\mathrm{a}}$ ed. em 1959).

, (1958). "El origen de la obra de arte" en Arte y poesía. México : F.C.E. (1 $1^{\mathrm{a}}$ ed. em 1935).

, (1989). Hölderlin y la esencia de la poesía. Barcelona: Anthropos ( $1^{\mathrm{a}}$ ed. em 1936).

HOFMANNSTHAL, Hugo von, (1996). Carta de Lord Chandos. Murcia : Cajamurcia (1 ${ }^{\mathrm{a}}$ ed. em 1902).

NIETZSCHE, Friedrich, (1974) "Sobre la verdad y la mentira en sentido extramoral" en El libro del filósofo. Madrid: Taurus ( $1^{\mathrm{a}} \mathrm{ed}$. em 1873).

(1979). La Gaya Ciencia. Barcelona : Olañeta (1 ${ }^{\mathrm{a}}$ ed. em 1882)

PARDO, José Luis, (1996). "La lengua de la intimidad. Fragmentos de una teoría de la pasión comunicativa". La intimidad, Valencia, Pretextos.

VALVERDE, José María, (1995). "Pensar y hablar”. Isegoría, no 11, Madrid.

VATTIMO, Gianni (1989). Más allá del sujeto. Nietzsche, Heidegger y la hermenéutica. Barcelona : Paidós (1ª ed. em 1981). 